\title{
Migraine prevalence, alexithymia, and post-traumatic stress disorder among medical students in Turkey
}

\author{
Hatice Balaban • Murat Semiz • İlteriş Ahmet Şentürk • \\ Önder Kavakçı $\cdot$ Ziynet Çınar $\cdot$ Ayfer Dikici $\cdot$ Suat Topaktaş
}

Received: 12 February 2012/ Accepted: 11 April 2012/Published online: 26 April 2012

(C) The Author(s) 2012. This article is published with open access at Springerlink.com

\begin{abstract}
The aim of this study was to investigate the prevalence of migraine, alexithymia, and post-traumatic stress disorder among medical students at Cumhuriyet University of Sivas in Turkey. A total of 250 medical students participated in this study and answered the questionnaires. The study was conducted in three stages: the self-questionnaire, the neurological evaluation, and the psychiatric evaluation. In the first stage, the subjects completed a questionnaire to assess migraine symptoms and completed the three-item Identification of Migraine Questionnaire, the Toronto Alexithymia Scale, and the Post-Traumatic Stress Disorder ChecklistCivilian Version Scale. The subjects who reported having a migraine underwent a detailed neurological evaluation conducted by a neurologist to confirm the diagnosis. In the final stage, the subjects with a migraine completed a psychiatric examination using the structured clinical interview for DSMIV-R Axis I. The actual prevalence of migraine among these medical students was $12.6 \%$. The students with a migraine were diagnosed with alexithymia and post-traumatic stress disorder more frequently than those without migraine. The Migraine Disability Assessment Scale scores correlated with the post-traumatic stress disorder scores. The results of this study indicate that migraine was highly prevalent among
\end{abstract}

H. Balaban $(\bowtie) \cdot$ İ. A. Şentürk · S. Topaktaş

Department of Neurology, Faculty of Medicine, Cumhuriyet University, 58140 Sivas, Turkey

e-mail: haticebalaban@yahoo.com

M. Semiz · Ö. Kavakçı · A. Dikici

Department of Psychiatry, Faculty of Medicine,

Cumhuriyet University, 58140 Sivas, Turkey

Z. Çınar

Department of Biostatistics, Faculty of Medicine, Cumhuriyet University, 58140 Sivas, Turkey medical students in Turkey and was associated with the alexithymic personality trait and comorbid psychiatric disorders including post-traumatic stress disorder. Treatment strategies must be developed to manage these comorbidities.

Keywords Prevalence $\cdot$ Migraine $\cdot$ Post-traumatic stress disorder $\cdot$ Alexithymia $\cdot$ Comorbidity $\cdot$ Medical students

\section{Introduction}

Migraine and tension-type headache are the most common primary headache types. Migraine is a neurologic disorder that represents a significant health problem due to the frequency and accompanying morbidity that includes disability and loss of performance [1-3]. Migraine has a lifetime prevalence of $12-18 \%$, which has been shown to be both age and gender dependent in community-based studies worldwide [4]. The lifetime prevalence of migraine in Turkey was found to be $10.9 \%$ in men and $21.8 \%$ in women in a nationwide epidemiological study [5]. In studies, a higher percentage of migraine headache have been reported in women; female hormones may be a factor responsible for the sex difference.

Previous studies have demonstrated an association between migraine and specific psychiatric disorders in the general population. Although the association between migraine and depression is the most widely reported, there are also strong associations between migraine and other psychiatric disorders and conditions [6-10]. Researchers have reported that anxiety disorder, post-traumatic stress disorder (PTSD), depression, and alexithymia are more frequently reported in adults with migraine [11-16].

Although the association among various psychiatric comorbidities and migraine is well established in adult 
case-control studies, the prevalence of these disorders in university students with migraine has not been examined in detail.

The social distribution of migraine has long been a subject of speculation. Epidemiological studies help clinicians understand the frequency and nature of the pain. Studies have also shown such interesting aspects as the risk factors related to socio-demographic status and genetic and environmental factors in populations [1, 17]. The epidemiology of migraine among medical students is of particular interest because migraine is the most common type of headache in young adults. Psychological and physical stressors are more common in medical students than the general population [18]. These stressors could be triggers for migraine in this population. The migraine prevalence was reported to be between 12.4 and $21.9 \%$ in Turkey using self-reporting measures [1, 2, 19]. Prevalence studies reported that migraine was highly prevalent among university students and was associated with impaired academic performance [1, 2, 19-21]. The results of studies in various countries have consistently shown that migraine sufferers report limited daily activities at work or at school [21]. In university students, a decreased school performance limits success, which may influence their future occupational performance. Furthermore, both migraines and the majority of psychiatric disorders are reported to begin during the college years. A detailed investigation of associated psychiatric conditions in university students is warranted because psychiatric comorbidities are already associated with poor performance in the activities of daily living among migraine sufferers [21].

PTSD is a condition in which an overwhelming traumatic event results in intense fear, helplessness, horror, and avoidance of stimuli associated with the trauma [13]. PTSD has been shown to worsen the chronicity and disability of patients with chronic pain. Pain and pain-related disability could be reduced with treatment for PTSD [16, 22]. de Leeuw et al. [14] reported that the consistency of PTSD symptoms appears to be more frequent in patients with recurrent headache than in the healthy population. Afari et al. [13] also found that PTSD symptoms following combat injury were associated with headache. A higher frequency of PTSD was reported in patients with migraine headache than the general population [16]. Peterlin et al. [15] reported an increased prevalence for PTSD in episodic migraine patients compared with subjects without headache in their study which is the largest and most substantial study on PTSD and migraine in the literature.

Interestingly, some symptoms that resemble PTSD including nightmares, intrusive visual images, insomnia, depression, and learning impairments have been frequently reported among medical students [23]. However, a correlation between the PTSD symptoms and migraine is still an understudied topic in medical students.

Alexithymia is a personality trait that is conceptualized as deficits in a person's ability to employ cognitive processes to identify, differentiate, and communicate one's affective states [24, 25]. Alexithymia and PTSD have been frequently reported among patients with chronic pain [24]. Interestingly, previous studies have found a correlation between alexithymia and PTSD symptoms. Studies have reported an association between a perceived difficulty in identifying and describing emotional states and the severity of PTSD symptoms [26, 27].

Although migraine is also prevalent among medical faculty, health sciences, and psychology students, previous studies have not adequately assessed comorbid psychiatric conditions and personality traits in this specific population $[28,29]$. Researchers have reported the prevalence of migraines using self-reporting instruments without performing neurological evaluations. Therefore, reliable studies in which individuals diagnosed with migraine are subjected to a detailed evaluation by a neurologist and psychiatrist are needed. Understanding the nature of the association between migraines and psychiatric disorders and conditions has implications for diagnosis and treatment. The occurrence of comorbidity may also provide clues to the aetiology of each disorder. The aim of this study is to investigate the actual prevalence of migraine and the comorbidity of alexithymia and PTSD among medical students at Cumhuriyet University of Sivas in Turkey.

\section{Materials and methods}

Participants and study design

The study was conducted with students of the Medical Faculty at Cumhuriyet University in Sivas, Turkey during the 2010-2011 school years. There are a total of 850 students at the Medical Faculty. Of these 850 students, 250 were selected with randomized stratified sampling ( $p=0.15, \alpha=0.01$, and $d=0.05$ ). Of the 250 students, 11 refused to participate in the study. To reach the 250 participant count, we gave the questionnaires to the next students when a student did not want to participate. The study was approved by the Medical Faculty Hospital Ethics Committee and consent was obtained from each subject.

The study incorporated three stages. In the first stage, the students were asked to complete a standardized questionnaire to establish a migraine diagnosis during a school visit (Appendix). The first part of the instrument consisted of questions regarding demographic characteristics including age, medical history, family history, family structure, family socioeconomic status, smoking habits, and alcohol 
use. The second part was composed of questions related to the 2004 diagnostic criteria for the International Headache Society (IHS) for migraines [30]. The ID Migraine, Toronto Alexithymia Scale (TAS), and PTSD Checklist-Civilian Version (PCL-C) were also used.

The subjects who reported migraine in the screening questionnaire participated in the second stage of the study. During this stage, a neurologist conducted a full neurological evaluation to confirm the migraine diagnosis. The neurological evaluation detailed a headache history and a neurological examination. The Turkish version of the Migraine Disability Assessment Scale (MIDAS) questionnaire was then administered to the students to assess failure due to migraine. In the third stage, students with migraine completed a psychiatric examination with the Structured Clinical Interview for DSM-IV-R Axis I (SCID-I). The psychiatric examination was performed by two psychiatrists (MS, AD). In addition, 31 students without migraine but with similar age and gender were selected randomly to complete the SCID-I. Finally, the SCID-I results of the groups were compared.

\section{Materials}

\section{Identification of migraine (ID Migraine ${ }^{T M}$ )}

As a widely used screening instrument for identifying migraine at primary health services, the ID Migraine is a three-question screening tool for migraines that has demonstrated good validity [31]. Each of the three items relates to a central diagnostic symptom of migraine: nausea, photophobia, and interference with activities. Each question is scored dichotomously with endorsements of two or more items suggesting probable migraine sensitivity and specificity. A positive predictive value on this test has been defined as 81, 75, and $93 \%$, respectively. The Turkish version of the ID Migraine ${ }^{\mathrm{TM}}$ screening test has previously been validated [32].

\section{Toronto Alexithymia Scale (TAS-20)}

The prevalence of alexithymia was investigated using the 20-item version of the Toronto Alexithymia Scale (TAS-20), Turkish version [33-35]. The three dimensions of the TAS-20 are the following: (1) difficulty identifying feelings, (2) difficulty describing feelings, and (3) externally oriented thinking. The total scores for the TAS-20 were categorized with a score $\geq 61$ indicating alexithymia and a score of $<61$ indicating no alexithymia [35].

\section{PTSD Checklist-Civilian Version $(P C L-C)$}

The PCL-C is a self-report measure used to assess the incidence of significant stressors and the prevalence of
PTSD symptoms [36]. The Turkish version of the PCL-C was performed by Kocabaşoğlu et al. [37]. Prior to completing this questionnaire, the respondent is asked to identify significant traumatic stressors from a 15 -item list that includes experiences such as military combat, violent attack, incarceration, natural or man-made disaster, severe auto accident, sudden injury/serious accident, observing someone else being hurt or killed, and learning that your child has a life-threatening illness [14].

\section{Migraine Disability Assessment Scale (MIDAS)}

The MIDAS questionnaire is used to gather information on a disability in terms of missed days of paid work (or school), housework (chores), and non-work time. The questions are asked regarding either days of missed activity or days during which productivity was reduced by at least $50 \%$. If productivity decreased to $50 \%$ or less, the day is considered missed [38]. The 4-point grading system for the MIDAS questionnaire is as follows: Grade I (scores ranging from 0 to 5), little or no disability; Grade II (scores ranging from 6 to 10), mild disability; Grade III (scores ranging from 11 to 20), moderate disability; and Grade IV (scores of 21 or greater), severe disability. The Turkish version of the MIDAS questionnaire was developed by Ertaş et al. [39].

\section{The Visual Analogue Scale (VAS)}

The VAS is a simple and commonly used method for evaluating variations in pain intensity [40]. The subjects are instructed to indicate the intensity of their pain by marking a 100-mm line anchored with terms that describe the extremes of pain intensity.

\section{The structured clinical interview for DSM-IV-R (SCID) I}

According to the DSM-IV, the SCID-I is a clinical interview comprised six structured modules that are utilized by an interviewer to determine whether an individual has one or more Axis-I disorders. The average application period is 25-60 min, and the evaluation is conducted with the patient individually. During the application, the interviewer uses an administration booklet with interview questions and a scoring sheet to record ratings. The psychiatric diagnosis is determined based on "current" and "lifetime" experiences [41]. Developed by First et al. in 1997 into a Turkish reliability study, an adaptation of the SCID-I was conducted by Özkürkçügil et al. [42]. For all diagnoses, the interviewer agreement was $98.1 \%$, and the kappa coefficient was 0.86 . For all diagnostic categories, the kappa coefficients changed between 0.52 and 1.00 and were significant $(p<0.001)$. 
Statistical analyses

Statistical analyses were performed using the Statistical Package for the Social Sciences (SPSS) Version 14.00. The data of categorical variables were presented as counts and percentages; the data of continuous variables were presented as the mean and SD. A comparison of variables between the groups was performed using the Independent $t$ test for numeric variables and the $\chi^{2}$ test for categorical data. First, the correlations between the MIDAS scores and the PTSD scores and the MIDAS scores and the alexithymia scores were tested using linear regression analysis. Then, a multivariate step-wise linear regression analysis was applied to the MIDAS scores, the PTSD scores and the alexithymia scores in students with migraines. In all analyses, $p$ values below 0.05 were considered significant.

\section{Results}

A total of 250 students answered the questionnaires in this study. Four 17-year-old students were excluded from the analysis. In total, 246 students between the ages of 18 and 26 years with a mean age of $20.85 \pm 2.10$ years were eligible in this study. Of the 246 students, 127 (52\%) were female, and $119(48 \%)$ were male. Table 1 displays the demographic and social characteristics of the 246 students.

Migraine-type headache were detected in 34 of 246 subjects using a self-reporting instrument; however, only 31 of the 34 subjects were diagnosed with migraine based on a personal neurological interview. Therefore, $215(87.3 \%)$ of the 246 subjects were migraine-free. The self-reported migraine prevalence was $13.8 \%$, whereas the actual migraine prevalence among the medical students was $12.6 \%$. Of these 31 subjects with migraine, $25(80.6 \%)$ were female, and $6(19.4 \%)$ were male. The mean age of disease onset was 16.87 years, and the average number of attacks per month was $5.96(\min 1-\max 15)$. The mean pain intensity was 5.48 ( $\min 3-\max 9)$. In addition, $27(87.1 \%)$ of 31 students had migraine without aura, whereas the remaining 4 students $(12.9 \%)$ had migraine with aura. No differences were found between the socioeconomic status of those students with migraine and those without. Similarly, smoking habits and alcohol use did not differ significantly between the groups. Table 2 shows the clinical characteristics of the migraine.

Only 3 of the students with migraine had previously consulted a physician for their headaches, whereas the remaining 28 students had not. None of the 31 students with migraine were being treated for the condition. Similarly, none had visited a psychiatrist prior to the study.

The MIDAS scores showed that $13(41.9 \%)$ students had minimal disability with a mean score of 3 . Five (16.1\%) students had mild disability with a mean score of 8. Six (19.3\%) had moderate disability with a mean score of 13 , and finally, seven (22.5\%) had severe disability with a mean score of 25 (Table 3 ).

PTSD was found in $13(5.2 \%)$ of the 246 subjects and was not detected in 233 of the 246 subjects. Of the 31
Table 1 Demographic characteristics of students

\begin{tabular}{|c|c|c|c|}
\hline & Total & Migraine & Non-migraine \\
\hline Number & 246 & 31 & 215 \\
\hline Age & $20.85 \pm 2.10$ & $20.90 \pm 1.70$ & $20.84 \pm 2.10$ \\
\hline \multicolumn{4}{|l|}{ Sex } \\
\hline Female & $127(51.6 \%)$ & $25(80.6 \%)$ & $102(47.4 \%)$ \\
\hline Male & $119(48.4 \%)$ & $6(19.4 \%)$ & $113(52.6 \%)$ \\
\hline \multicolumn{4}{|c|}{ Marital status } \\
\hline Single & $241(97.9 \%)$ & $30(97 \%)$ & $211(98.1 \%)$ \\
\hline Married & $5(2.1 \%)$ & $1(3 \%)$ & $4(1.9 \%)$ \\
\hline \multicolumn{4}{|c|}{ Family history of headache } \\
\hline Yes & $85(34.6 \%)$ & $22(71 \%)$ & $63(29 \%)$ \\
\hline No & $161(65.4 \%)$ & $9(29 \%)$ & $152(71 \%)$ \\
\hline \multicolumn{4}{|c|}{ Family history of neurological disease } \\
\hline Yes & $4(1.7 \%)$ & $0(0 \%)$ & $4(1.9 \%)$ \\
\hline No & $242(98.3 \%)$ & $31(100 \%)$ & $211(98.1 \%)$ \\
\hline \multicolumn{4}{|l|}{ Smoking } \\
\hline Yes & $22(9 \%)$ & $4(13 \%)$ & $18(8.4 \%)$ \\
\hline No & $224(91 \%)$ & $27(87 \%)$ & $197(91.6 \%)$ \\
\hline \multicolumn{4}{|c|}{ Alcohol use } \\
\hline Yes & $22(9 \%)$ & $6(19.3 \%)$ & $16(7.4 \%)$ \\
\hline No & $224(91 \%)$ & $25(80.7 \%)$ & $199(92.6 \%)$ \\
\hline
\end{tabular}


Table 2 Clinical characteristics of migraine in students

\begin{tabular}{ll}
\hline Characteristics & Number/Total \\
\hline Pain level & $10 / 31$ \\
Mild & $16 / 31$ \\
Moderate & $5 / 31$ \\
Severe & \\
Frequency of pain at 3 months & $16 / 31$ \\
$0-5$ & $14 / 31$ \\
$6-10$ & $1 / 31$ \\
11 & \\
Mean duration of attacks & $13 / 31$ \\
$4-5 \mathrm{~h}$ & $3 / 31$ \\
$6-11 \mathrm{~h}$ & $4 / 31$ \\
$12-23 \mathrm{~h}$ & $11 / 31$ \\
$24 \mathrm{~h}$ or more & \\
Types of migrane & $4(12.9 \%)$ \\
With aura & $27(87.1 \%)$ \\
Without aura &
\end{tabular}

Table 3 MIDAS grades of the students

\begin{tabular}{lc}
\hline MIDAS grade & Number $n(\%)$ \\
\hline Grade I & $13(42)$ \\
Grade II & $5(16)$ \\
Grade III & $6(19)$ \\
Grade IV & $7(23)$ \\
\hline
\end{tabular}

students with migraines, $7(22.5 \%)$ were found to have PTSD, whereas $6(2.8 \%)$ of the 215 migraine-free students had PTSD (odds ratio $=10.16,95 \% \mathrm{CI}=3.16-32.71$, $p=0.001$ ). A significant correlation was found between MIDAS scores and PTSD scores by linear regression analysis $\left(t=2.95, r^{2}=0.23, r=0.48 p=0.006\right)$.

Alexithymia was found in only $9(3.6 \%)$ of the 246 subjects. However, alexithymia was detected in $4(12.9 \%)$ of the 31 students with migraine. Only 5 (2.3\%) of the 215 migraine-free students had alexithymia $(\mathrm{ODS}=6.33$, $95 \% \mathrm{CI}=1.57-24.60, p=0.01)$. The students with migraine had significantly higher rates of alexithymia (Table 4). The results of linear regression analysis showed a correlation between alexithymia and MIDAS sores $\left(t=2.40, r^{2}=0.16, r=0.41 p=0.023\right)$.

Finally, a multivariate linear regression model was designed between alexithymia scores, PTSD scores, and MIDAS scores. PTSD scores correlated with MIDAS scores $\left(t=2.06, r^{2}=0.27, r=0.55, p=0.04\right)$; a multivariate regression analysis did not show a correlation between alexithymia and MIDAS scores.

When the results obtained using the SCID-I were examined, a current SCID-I psychiatric diagnosis was found in 9 (29\%) of the 31 subjects with migraine and $2(6.45 \%)$ of the
Table 4 Association between migraine, PTSD, and alexithymia

\begin{tabular}{|c|c|c|c|c|c|c|}
\hline & $\begin{array}{l}\text { With } \\
\text { migraine }\end{array}$ & $\%$ & $\begin{array}{l}\text { Without } \\
\text { migraine }\end{array}$ & $\%$ & Total & $p$ \\
\hline \multicolumn{7}{|c|}{ PTSD-by PCL-C } \\
\hline Yes & 7 & 22.5 & 6 & 2.8 & 13 & \multirow[t]{2}{*}{$<0.001$} \\
\hline No & 24 & 77.5 & 209 & 97.2 & 233 & \\
\hline \multicolumn{7}{|c|}{ PTSD-by SCID-I } \\
\hline Yes & 4 & 12.9 & 0 & 0 & 4 & \multirow[t]{2}{*}{$<0.001$} \\
\hline No & 27 & 87.1 & 31 & 100 & 58 & \\
\hline \multicolumn{7}{|c|}{ Alexithymia } \\
\hline Yes & 4 & 12.9 & 5 & 2.3 & 9 & \multirow[t]{2}{*}{$<0.01$} \\
\hline No & 27 & 87.1 & 210 & 97.7 & 237 & \\
\hline
\end{tabular}

PTSD-by $P C L-C$ diagnosis of post-traumatic stress disorder by $P T S D$ Checklist-Civilian Version, PTSD-by SCID-I diagnosis of post-traumatic stress disorder by Structured Clinical Interview for DSM-III-R Axis I

migraine-free subjects $\left(\chi^{2}=5.41, p=0.02\right)$. A total of 15 $(48.4 \%)$ of the 31 students with migraine were found to have had a lifetime SCID-I psychiatric diagnosis, whereas only 6 $(19.4 \%)$ of the students without migraine had a lifetime SCID-I psychiatric diagnosis. When the two groups were compared in terms of lifetime SCID-I diagnosis, the difference was significant $\left(\chi^{2}=5.83, p=0.01\right)$ (Table 5).

\section{Discussion}

The present study examined migraine prevalence and its association with PTSD and alexithymia in a sample of 246 medical students. PTSD and alexithymia were found to be significantly higher in a selected cohort of medical students. The subjects with migraines were interviewed and evaluated by a neurologist and a psychiatrist in this study. The diagnosis of migraine was determined using the 2004 IHS criteria, which are utilized in epidemiological studies due to their high sensitivity [30]. The prevalence of migraine was found to be $12.6 \%$. Migraine without aura was the most common type of migraine found in this study. The observed migraine prevalence was similar to those reported in larger population studies that used structured diagnostic interviews. The prevalence of migraine has been reported to be between 12.4 and $21.9 \%$ among university students in Turkey $[1,2,19]$. However, the prevalence of migraine among medical students reportedly ranges from 11 to $40 \%$ worldwide $[3,28$, 29]. A higher prevalence has been reported in some studies. The differences may be attributed to the methodological differences among these studies. Different self-reporting questionnaires may result in different prevalence values. The use of a self-administered questionnaire might lead to misunderstanding of some questions with the risk of certain subjectivity in the answers. The examination of subjects by a 
Table 5 Results of the SCID-I evaluation of the students

\section{PTSD post-traumatic stress disorder, panic dis panic disorder, spec phobia specific phobia, soc phobia social phobia, gen anx dis generalized anxiety disorder, $O C D$ obsessive compulsive disorder}

\begin{tabular}{|c|c|c|c|c|}
\hline & \multicolumn{4}{|l|}{ SCID-I } \\
\hline & \multicolumn{2}{|c|}{ Current SCID-I } & \multicolumn{2}{|c|}{ Lifetime SCID-I } \\
\hline & Migraineurs & Nonmigraineurs & Migraineurs & Nonmigraineurs \\
\hline PTSD & 4 & & 4 & \\
\hline Panic dis & 2 & 1 & 2 & 1 \\
\hline Depression & 1 & 1 & 4 & 3 \\
\hline Spec phobia & 1 & & 1 & 1 \\
\hline Soc phobia & & & 1 & \\
\hline Dysthymia & 1 & & & \\
\hline Gen anx dis & & & 2 & 1 \\
\hline OCD & & & 1 & \\
\hline Total & 9 & 2 & 15 & 6 \\
\hline
\end{tabular}

neurologist enabled the confirmation of the screening results and the exclusion of other types of headache.

PTSD occurs as a result of exposure to extreme traumatic stressors that arouse feelings of intense fear, helplessness, and horror in exposed individuals [22]. There is increasing support in the literature for a strong association between migraine and PTSD in adult migraine patients. High PTSD prevalence rates of $22-50 \%$ have been reported in individuals with migraine in previous studies of adult subjects fulfilling the criteria for PTSD [13, 14, 22].

In an examination of the diagnostic overlap between PTSD and migraines, Peterlin et al. [16] reported that migraine sufferers with PTSD had a significantly greater disability than those without PTSD. However, Ifergane and colleagues [43] also examined the relationship between PTSD and migraine, and they reported that the prevalence of PTSD in migraine patients was not significantly different than in the general population. The prevalence of PTSD with migraine was studied in a large general population sample of over 5,600 adults. The authors found a 12-month prevalence of PTSD to be $14.3 \%$ in episodic migraine patients compared to $2.1 \%$ in those with no headaches. In addition, the life-time prevalence of PTSD was $21.5 \%$ in episodic migraineurs compared to $4.5 \%$ in subjects without headaches. An increased prevalence of PTSD in chronic daily headache patients was also reported in that study [15]. The results of the present study showed that PTSD with migraine was as high in medical students as in the general population.

The exact pathophysiological mechanism of migraine and associated PTSD is not precisely known. An increased sensitivity to stressors has been described in migraine and may be related to PTSD pathophysiology. Alterations in serum serotonin levels have been linked to both PTSD and migraine pathogenesis. The most widely accepted theory is dysfunction of the hypothalamic- pituitary- adrenal axis [15, 44-47].

People with alexithymia have difficulty in expressing their feelings. The term was initially used to denote an adaptive style that creates a tendency to develop psychosomatic symptoms [11, 48]. Several studies have analysed the prevalence and impact of alexithymia among chronic pain patients, and these studies have resulted in a better understanding of the relationship between chronic pain and personality traits [24, 25]. A limited number of studies have examined the correlation between alexithymia and migraine.

Wise et al. [49] studied anxiety, depression, and alexithymia in patients with tension-type headache and migraine. The authors found no difference between subjects diagnosed with migraine and those with tension-type headache with regards to alexithymia, levels of anxiety or depression. In contrast, Lumley et al. [50] reported that the alexithymia personality trait has a negative impact on the pain severity of chronic pain patients including migraine headaches. Muftuoglu et al. [11] found that migraine patients were considerably more depressed, anxious, and alexithymic than the healthy controls. Yalug et al. [12] reported a significantly higher score in measures of depression but not alexithymia or anxiety in chronic migraine patients compared to episodic migraine patients. However, significant correlations were noted between depression, anxiety, and alexithymia in the study by Yalug et al. A high correlation has been reported among alexithymia, anxiety, and depression scores, which may indicate that alexithymia is associated with psychological distress. Our findings also indicate that alexithymia is common among medical students with migraine.

In the present study, the prevalence of PTSD and alexithymia was significantly higher in subjects with migraine than in those without migraines. The results of screening tests revealed that seven students with migraines had PTSD. Nevertheless, when those students were evaluated using the SCID-I, only four of them met the criteria for a PTSD diagnosis. This difference highlights the fact that self-report tests and psychiatric interviews yield different prevalence rates as stated in the "Introduction" of this paper. The data obtained from self-reporting evaluations may help to detect cases under the threshold but may also be limited to the perceptions of the individual, making them unreliable. 
The results of studies conducted in different countries support the association between migraine, PTSD and alexithymia in adults. In the present study, higher rates of PTSD and alexithymia were found in students with migraines than in migraine-free students. Interestingly, a high rate of alexithymia has been reported in PTSD cases [26, 27, 48]. Previous studies have shown a relationship between PTSD and alexithymia. This relationship needs to be explained in migraineurs.

The results of several studies have shown that PTSD has a negative impact on the abilities of chronic pain patients. In this study, a significant correlation was found between the MIDAS disability score and the PTSD score in students with migraine. The students with migraine appear to be characterized by a higher prevalence of PTSD and alexithymia than individuals in the general population.

One strength of the present study is that the students diagnosed with migraine were evaluated by a neurologist and a psychiatrist in the second and third stages of the study, respectively, which allowed for the diagnoses of migraine headache and psychiatric conditions to be performed based on objective measures. On the other hand, this study has some limitations. First, only 31 migraineurs students were detected in this selected population, and this count may not allow our results to be generalizable and may not represent the whole population. Moreover, we evaluated alexithymia in students only by a self-reported questionnaire, and we did not investigate the association between alexithymia scores and PTSD scores.

In conclusion, both PTSD and alexithymia are common in medical students with migraine, and PTSD symptoms correlate with pain-related disability. The finding that the majority of the students with migraine had not visited a neurologist or a psychiatrist shows that there is a lack of diagnosis and treatment in this population. The identification and treatment of PTSD and alexithymia in medical students with migraine are an important and potentially modifiable health state. Taken together, the results of previous studies with adults and the present study suggest that the treatment of PTSD and alexithymia positively influence the levels of pain and migraine-related disability in medical students.

Acknowledgments The authors thank Ayşegül Kartal for her assistance.

Conflict of interest The authors have no financial obligations to disclose related to this study.

Open Access This article is distributed under the terms of the Creative Commons Attribution License which permits any use, distribution, and reproduction in any medium, provided the original author(s) and the source are credited.

\section{Appendix}

See Table 6.
Table 6 Migraine headache questionnaire form

\begin{tabular}{|c|c|c|c|c|}
\hline Subject number: & & & & \\
\hline Name: & & & & \\
\hline Class: & & & & \\
\hline Age: & & & & \\
\hline Gender: & Female & Male & & \\
\hline Marital status: & Single & Married & & \\
\hline Family type: & Nuclear & Extended & Other & \\
\hline Socioeconomic status: & Lower & Middle & Upper & \\
\hline Headache history in family: & Yes & No & & \\
\hline History of neurological disease in family: & Yes & No & & \\
\hline Your systemic disease: & Yes & No & & \\
\hline Your psychiatric disease: & Yes & No & & \\
\hline Smoking habits: & Yes & No & & \\
\hline Alcohol use: & Yes & No & & \\
\hline $\begin{array}{l}\text { Have you ever had five or more headache } \\
\text { unrelated to any other illness } \\
\text { during the last } 6 \text { months? }\end{array}$ & & & & \\
\hline & Yes & No & & \\
\hline Headache characteristics: & Throbbing & Burning & Pressing & \\
\hline Localization: & Unilateral & Bilateral & & \\
\hline Mean duration of headache: & & & & \\
\hline Associate symptoms: & Nausea & Vomiting & Photophobia & Phonophobia \\
\hline Pain intensity: & Mild & Moderate & Severe & \\
\hline $\begin{array}{l}\text { Aggravation by or causing avoidance } \\
\text { of physical activity: }\end{array}$ & Yes & No & & \\
\hline
\end{tabular}




\section{References}

1. Kurt S, Kaplan Y (2008) Epidemiological and clinical characteristics of headache in university students. Clin Neurol Neurosurg 110:46-50

2. Demirkırkan MK, Ellidokus H, Boluk E (2006) Prevalence and clinical characteristics of migraine in university students in Turkey. Thoku J Exp Med 208:87-92

3. Adoukonou T, Houinato D, Kankouan J, Makoutode M, Paraiso M, Tehindrazanarivelo A, Viader F, Preux PM (2009) Migraine among university students in Cotonou (Benin). Headache 49(6):887-893

4. Breslau N, Rasmussen BK (2001) The impact of migraine: epidemiology, risk factors and comorbidities. Neurology 56:4-12

5. Zarifoğlu M, Karli N, Taşkapilioğlu O (2008) Can ID migraine be used as a screening test for adolescent migraine? Cephalalgia 28(1):65-71

6. Hamelsky SW, Lipton RB (2006) Psychiatric comorbidity of migraine. Headache 46(9):1327-1333

7. Pompili M, Serafini G, Di Cosimo D, Dominici G, Innamorati M, Lester D, Forte A, Girardi N, De Filippis S, Tatarelli R, Martelletti P (2010) Psychiatric comorbidity and suicide risk in patients with chronic migraine. Neuropsychiatr Dis Treat 7(6):81-91

8. Breslau N, Schultz LR, Stewart WF, Lipton RB, Lucia VC, Welch KMA (2000) Headache and major depression: is the association specific to migraine? Neurology 54:308-313

9. Breslau N, Lipton RB, Stewart WF, Schultz LR, Welch KMA (2003) Comorbidity of migraine and depression: investigating potential etiology and prognosis. Neurology 60:1308-1312

10. Baskin SM, Smitherman TA (2009) Migraine and psychiatric disorders: comorbidities, mechanisms, and clinical applications. Neurol Sci 30(1):61-65

11. Muftuoglu MN, Herken H, Demirci H, Virit O, Neyal A (2004) Alexithymic features in migraine patients. Eur Arch Psychiatry Clin Neurosci 254(3):182-186

12. Yalug I, Selekler M, Erdogan A, Kutlu A, Dundar G, Ankarali H, Aker T (2010) Correlations between alexithymia and pain severity, depression, and anxiety among patients with chronic and episodic migraine. Psychiatry Clin Neurosci 64(3):231-238

13. Afari N, Harder LH, Madra NJ, Heppner PS, Moeller-Bertram T, King C, Baker DG (2009) PTSD, combat injury, and headache in veterans returning from Iraq/Afghanistan. Headache 49(9):12671276

14. de Leeuw R, Schmidt JE, Carlson CR (2005) Traumatic stressors and post-traumatic stress disorder symptoms in headache patients. Headache 45(10):1365-1374

15. Peterlin BL, Rosso AL, Sheftell FD, Libon DJ, Mossey JM, Merikangas KR (2011) Post-traumatic stress disorder, drug abuse and migraine: new findings from the National Comorbidity Survey Replication (NCS-R). Cephalalgia 31(2):235-244

16. Peterlin BL, Tietjen GE, Brandes JL, Rubin SM, Drexler E, Lidicker JR, Meng S (2009) Posttraumatic stress disorder in migraine. Headache 49(4):541-551

17. Mitsikostas DD, Gatzonis S, Thomas A, Kalfakis N, Ilias A, Papageoergiou C (1996) An epidemiological study of headaches among medical students in Athens. Headache 36(9):561-564

18. Dyrbye LN, Thomas MR, Shanafelt TD (2006) Systematic review of depression, anxiety, and other indicators of psychological distress among U.S. and Canadian medical students. Acad Med 81(4):354-373

19. Bicakci S, Bozdemir N, Over F, Saatci E, Sarica Y (2008) Prevalence of migraine diagnosis using ID migraine among university students in southern Turkey. J Headache Pain 9(3):159-163
20. Bigal ME, Bigal JM, Betti M, Bordini CA, Speciali JG (2001) Evaluation of the impact of migraine and episodic tension-type headache on the quality of life and performance of a university student population. Headache 41(7):710-719

21. Smitherman TA, McDermott MJ, Buchanan EM (2011) Negative impact of episodic migraine on a university population: quality of life, functional impairment, and comorbid psychiatric symptoms. Headache 51(4):581-589

22. Peterlin BL, Tietjen G, Meng S, Lidicker J, Bigal M (2008) Posttraumatic stress disorder in episodic and chronic migraine. Headache 48(4):517-522

23. O'Carroll RE, Whiten S, Jackson D, Sinclair DW (2002) Assessing the emotional impact of cadaver dissection on medical students. Med Educ 36(6):550-554

24. Lumley MA, Smith JA, Longo DJ (2002) The relationship of alexithymia to pain severity and impairment among patients with chronic myofascial pain: comparisons with self-efficacy, catastrophizing, and depression. J Psychosom Res 53(3):823-830

25. Salminen JK, Saarijärvi S, Toikka T, Kauhanen J, Aärelä E (2006) Alexithymia behaves as a personality trait over a 5-year period in Finnish general population. J Psychosom Res 61(2):275-278

26. Frewen PA, Lanius RA, Dozois DJ, Neufeld RW, Pain C, Hopper JW, Densmore M, Stevens TK (2008) Clinical and neural correlates of alexithymia in posttraumatic stress disorder. J Abnorm Psychol 117(1):171-181

27. Frewen PA, Pain C, Dozois DJ, Lanius RA (2006) Alexithymia in PTSD: psychometric and FMRI studies. Ann N Y Acad Sci 1071:397-400

28. Ferri-de-Barros JE, Alencar MJ, Berchielli LF, Castelhano LC Jr (2011) Headache among medical and psychology students. Arq Neuropsiquiatr 69(3):502-508

29. Amayo EO, Jowi JO, Njeru EK (2002) Headache associated disability in medical students at the Kenyatta National Hospital. Nairobi East Afr Med J 79(10):519-523

30. Headache Classification Committee of the International Headache Society (2004) The International Classification of Headache Disorders, 2nd Edition. Cephalalgia 24(1):1-159

31. Lipton RB, Dodick D, Sadovsky R, Kolodner K, Endicott J, Hettiarachchi J, Harrison W, ID Migraine validation study (2003) A self-administered screener for migraine in primary care: the ID migraine validation study. Neurology 61(3):375-382

32. Siva A, Zarifoglu M, Ertas M, Saip S, Karli HN, Baykan B, Keskinaslan A, Senocak M (2008) Validity of the ID-migraine screener in the workplace. Neurology 70(16):1337-1345

33. Bagby RM, Parker JDA, Taylor GJ (1994) The twenty-item Toronto Alexithymia Scale-I: item selection and cross-validation of the factor structure. J Psychosom Res 38:23-32

34. Bagby RM, Taylor GJ, Parker JDA (1994) The Twenty-item Toronto Alexithymia Scale-II convergent, discriminant, and concurrent validity. J Psychosom Res 38:33-40

35. Kose S, Sayar K, Gulec H, Evren C, Borckardt J (2005)The Turkish version of the 20-Item Toronto Alexithymia Scale (TAS20): reliability, validity, and factorial structure. Society of Biological Psychiatry Symposium, May 19-22, Atlanta, GA

36. Weathers FW, Huska JA, Keane TM (1991) PCL-C for DSM-IV. National Center for PTSD-Behavioral Science Division, Boston

37. Kocabaşoğlu N, Özdemir AÇ, Yargıç İ, Geyran P (2005) Türkçe PTSD Checklist-Civilian Version (PCL-C) ölçeğinin geçerlilik ve güvenilirliği. Yeni Symposium 43(3):126-134

38. Bigal ME, Rapoport AM, Lipton RB, Tepper SJ, Sheftell FD (2003) Assessment of migraine disability using the migraine disability assessment (MIDAS) questionnaire: a comparison of chronic migraine with episodic migraine. Headache 43(4):336342 
39. Ertaş M, Siva A, Dalkara T, Uzuner N, Dora B, Inan L, Idiman F, Sarica Y, Selçuki D, Sirin H, Oğuzhanoğlu A, Irkeç C, Ozmenoğlu M, Ozbenli T, Oztürk M, Saip S, Neyal M, Zarifoğlu M, Turkish MIDAS group (2004) Validity and reliability of the Turkish Migraine Disability Assessment (MIDAS) questionnaire. Headache 44(8):786-793

40. Chapman CR, Casey KL, Dubner R, Foley KM, Gracely RH, Reading AE (1985) Pain measurement: an overview. Pain 22(1): $1-31$

41. First MB, Spitzer RL, Gibbon M, Williams JBW (1996) Structured clinical interview for DSM-IV Axis I disorders, clinician version (SCID-CV). American Psychiatric Press Inc, Washington, DC

42. Özkürkçügil A, Aydemir Ö, Yıldız M, Danacı AE, Köroğlu E (1999) DSM-IV eksen I bozuklukları için yapılandırılmış klinik görüşmenin Türkçe'ye uyarlanması ve güvenilirlik çalışması. İlaç ve Tedavi Dergisi 12:233-236

43. Ifergane G, Buskila D, Simiseshvely N, Jotkowitz A, Kaplan Z, Cohen H (2009) Post-traumatic stress disorder is not over-represented in a sample population of migraine patients. Eur J Intern Med 20(2):182-185

44. Shalev AY, Videlock EJ, Peleg T, Segman R, Pitman RK, Yehuda R (2008) Stress hormones and post-traumatic stress disorder in civilian trauma victims: a longitudinal study. Part I: HPA axis responses. Int J Neuropsychopharmacol 11(3):365-372

45. Denuelle M, Fabre N, Payoux P, Chollet F, Geraud G (2007) Hypothalamic activation in spontaneous migraine attacks. Headache 47(10):1418-1426

46. Izzati-Zade KF (2008) The role of serotonin in the pathogenesis and clinical presentations of migraine attacks. Neurosci Behav Physiol 38(5):501-505

47. Pinna G, Rasmusson AM (2012) Up-regulation of neurosteroid biosynthesis as a pharmacological strategy to improve behavioural deficits in a putative mouse model of post-traumatic stress disorder. J Neuroendocrinol 24(1):102-116

48. Grabe HJ, Spitzer C, Freyberger HJ (2004) Alexythymia and personality in relation to dimensions of psychopathology. Am J Psychiatry 161:1299-1301

49. Wise TN, Mann LS, Jani N, Jani S (1994) Illness beliefs and alexithymia in headache patients. Headache 34(6):362-365

50. Lumley MA, Radcliffe AM, Macklem DJ, Mosley-Williams A, Leisen JC, Huffman JL, D'Souza PJ, Gillis ME, Meyer TM, Kraft CA, Rapport LJ (2005) Alexithymia and pain in three chronic pain samples: comparing Caucasians and African Americans. Pain Med 6(3):251-261 